See discussions, stats, and author profiles for this publication at: https://www.researchgate.net/publication/322704751

\title{
Cardiorespiratory repercussions according to the abdominal circumference measurement of men with obstructive respiratory disorder submitted to respiratory physiotherapy
}

Article in Physiotherapy Theory and Practice · January 2018

DOI: 10.1080/09593985.2018.1430195

CITATION

1

6 authors, including:

Bruno Martinelli

22 PUBLICATIONS 56 CITATIONS

SEE PROFILE

José Robison

São Paulo State University

11 PUBLICATIONS 682 CITATIONS

SEE PROFILE
READS

71

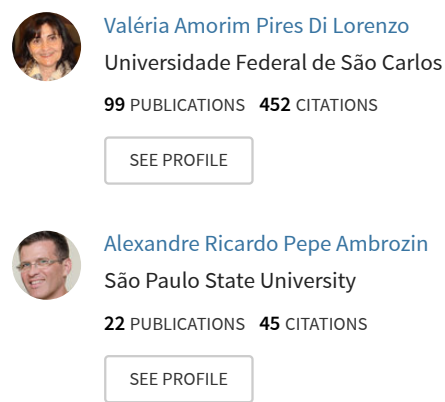

Some of the authors of this publication are also working on these related projects:

Activities of daily living assessment and the effect of two resistance training intensities as part of a combined training in activities of daily living and quality of life in patients with COPD View project

Reliability and Validity of the six-minute step test in patients with Chronic Obstructive Pulmonary Disease and its association with mortality predictor indices View project 


\section{Cardiorespiratory repercussions according to the abdominal circumference measurement of men with obstructive respiratory disorder submitted to respiratory physiotherapy}

Bruno Martinelli, Valéria Amorim Pires Di Lorenzo, Robison José Quitério, Alexandre Ricardo Pepe Ambrozin, Eduardo Aguilar Arca \& Maurício Jamami

To cite this article: Bruno Martinelli, Valéria Amorim Pires Di Lorenzo, Robison José Quitério, Alexandre Ricardo Pepe Ambrozin, Eduardo Aguilar Arca \& Maurício Jamami (2018):

Cardiorespiratory repercussions according to the abdominal circumference measurement of men with obstructive respiratory disorder submitted to respiratory physiotherapy, Physiotherapy Theory and Practice, DOI: 10.1080/09593985.2018.1430195

To link to this article: https://doi.org/10.1080/09593985.2018.1430195

Published online: 25 Jan 2018.

Submit your article to this journal $₫$

Џ Article views: 4

Q View related articles $ک$

View Crossmark data \lceil 


\section{Cardiorespiratory repercussions according to the abdominal circumference measurement of men with obstructive respiratory disorder submitted to respiratory physiotherapy}

Bruno Martinelli, PhD, $\mathrm{PT}^{\mathrm{a}}$, Valéria Amorim Pires Di Lorenzo, PhD, $\mathrm{PT}{ }^{\mathrm{a}}$, Robison José Quitério, PhD, $\mathrm{PT}{ }^{\mathrm{b}}$, Alexandre Ricardo Pepe Ambrozin, PhD, PT ${ }^{\mathrm{b}}$, Eduardo Aguilar Arca, PhD, PTc, and Maurício Jamami, PhD, $\mathrm{PT}^{\mathrm{a}}$

aDepartment of Postgraduate Program in Physical Therapy, Federal University of São Carlos - UFSCar, São Carlos, São Paulo, Brazil; 'Department of Physical Therapy, São Paulo State University - UNESP, Marília, São Paulo, Brazil; 'Department of Postgraduate Program in Physical Therapy, University of Sagrado Coração - USC, Bauru, São Paulo, Brazil

\begin{abstract}
Purpose: To examine the effect of respiratory physiotherapy among men with obstructive respiratory disorder, in relation to abdominal circumference (AC). Methods: Quasi-experimental study including 26 men split into two groups according to $A C(\mathrm{~cm}): 1)<102\left(A C_{\text {risk-free }}\right)$; and 2$) \geq 102\left(A C_{\text {risk }}\right)$. Heart rate variability (HRV), diastolic blood pressure (DBP), oxygen saturation $\left(\mathrm{SpO}_{2}\right), \mathrm{FEV}_{1} / \mathrm{FVC}$, slow vital capacity (SVC), inspiratory capacity (IC), maximal inspiratory pressure $\left(\mathrm{PI}_{\max }\right)$, thoracoabdominal amplitude (AI) were measured: before $\left(M_{1}\right) ; 5$ min after the physiotherapy (i.e. breathing exercises for airway clearance and active kinesiotherapy) $\left(M_{2}\right)$; and at follow-up, 30 min after physiotherapy $\left(M_{3}\right)$. Results: The groups differed in age, body mass index and body fat \%. At $M_{2} I C$ was different between groups $\left(A C_{\text {risk-free }}<\right.$ $A C_{\text {risk }}$ ). There was an increase in $\mathrm{HRV}$ indexes, $\mathrm{PI}_{\text {max }}, \mathrm{SpO}_{2}$, axillary $\mathrm{Al}, \mathrm{FEV}{ }_{1} / \mathrm{FVC}$, and reduction in $\mathrm{HR}$ for $A C_{\text {risk-free. }}$ There was a decrease in $\mathrm{Al}$ and an increase in $\mathrm{DBP}$ for $A C_{\text {risk. }}$. Conclusion: In men with obstructive respiratory disorder, increased AC measurement limited the thoracoabdominal expansibility and induced a rise of the DBP. Respiratory physiotherapy promotes an increase of cardiac modulation and inspiratory capacity for men with obstructive respiratory disorder.
\end{abstract}

\section{ARTICLE HISTORY}

Received 3 November 2016

Revised 26 April 2017

Accepted 7 June 2017

\section{KEYWORDS}

Physical therapy techniques; airway obstructions; circulatory and respiratory physiological phenomenon; respiratory function test; obesity

\section{Introduction}

Both obstructive respiratory disorder (Sidney et al., 2005) and abdominal obesity (Huxley et al., 2010) are factors that contribute for the increase of mortality and hospitalization of individuals, mainly because of respiratory and cardiovascular complications. Thus, the coexistence of these two clinical situations requires attention, since their occurrence is very common. It is known that individuals with airway obstruction disorders, especially those with COPD, can present alterations in cardiac autonomic modulation with a lower heart rate variability (HRV), characterizing damage in baroreflex sensibility and vagal reduction of the sinus node (Pantoni et al., 2007; Rossi et al., 2014). Furthermore, the increase in abdominal circumference (AC) is associated with reductions of HRV (Poliakova et al., 2012; Rossi et al., 2015) and in $\mathrm{FEV}_{1}$, indicating airways obstruction that may be caused by the dynamic compression of airways (Chen et al., 2001). HRV can be used to evaluate interventions and interpretations of physiological conditions (Ferreira et al., 2013; Pumprla et al., 2002), since it reflects: cardiac autonomic nervous activity; gravity of cardiac and noncardiac diseases; and predict survival rates and prognosis (European Society of Cardiology and the North American Society of Pacing and Electrophysiology, 1996; Kleiger, Stein, and Bigger, 2005).

Physiotherapy treatment for individuals with obstructive respiratory disorder and obesity can have improved outcomes (Sharp, 1985). Respiratory physiotherapy is essential in these cases, since it facilitates the mucociliary clearance, decreasing the retention of secretion in the airway and improving the respiratory compliance (Schans, 2007). Manual respiratory techniques (e.g. thoracic vibration) can increase expired tidal volume (TV), without changing hemodynamic variables. On the other hand, respiratory control by pursed-lip and diaphragmatic breathing decreases breathing frequency ( $\mathrm{f}$ ), improves minute volume (MV), partial gas pressures, $\mathrm{SpO}_{2}$, dyspnea, tolerance to exercise and functional limitations, and also can change the cardiac autonomic control (Cooke et al., 1998). A potential mechanism for improvement is decreased narrowing of airways during expiration, which

CONTACT Bruno Martinelli, PhD, PT bnomartinelli@yahoo.com.br $\Theta$ Department of Postgraduate Program in Physical Therapy, Federal University of São Carlos - UFSCar, São Carlos, São Paulo, Brazil.

(c) 2018 Taylor \& Francis 
favors global pulmonary ventilation and reduces the respiratory symptoms and hyperventilation (Ali, Talwar, and Jain, 2014; Bruurs, Giessen, and Moed, 2013; Dechman and Wilson, 2004; Lan et al., 2013; Rodrigues, Alves, and Gonçalves, 2012).

Studying the behavior of cardiorespiratory variables after physiotherapy intervention will allow us to understand the effects in relation to cardiac control and the possible risks and benefits to individuals with airway obstruction respiratory and increased abdominal obesity who have a tendency for cardiovascular diseases.

It is believed that respiratory physiotherapy intervention improves cardiorespiratory function in men with obstructive respiratory disorder and increased AC measurement. This study aimed at evaluating the differences among men with obstructive respiratory disorder according to the measure of $\mathrm{AC}$, and analyzing the cardiorespiratory and metabolic acute responses resulting from a session of respiratory physiotherapy.

\section{Methods}

This study was a prospective clinical trial, quasi-experimental with sampling criteria by convenience, approved by the Research Ethics Committee of Universidade do
Sagrado Coração (757.430), Clinical Trials Identifier: NCT02217423.

Twenty-six participants, admitted into State Hospitals in the city of Bauru/SP, participated in this study. The flow of participation can be seen in Figure 1. The inclusion criteria were: men over 18 years of age; 10 -day maximum hospital admittance; $\mathrm{VEF}_{1} / \mathrm{FVC}<70 \% ; \mathrm{SpO}_{2} \geq 88 \%$ in ambient air; hemodynamic stability; and the ability to understand the commands for the evaluative tests. The exclusion criteria were: dermal chest injury; Borg scale (dyspnea) > 5; sudden weight change; ascites; nephrotic syndrome; congestive heart failure; and cirrhosis.

The participants that meet the inclusion criteria $(n=26)$ were divided into two groups according to the AC $(\mathrm{cm})$ measurement value that represents increased risks for cardiovascular diseases: 1) $\mathrm{AC}_{\text {risk }}$ $(\mathrm{AC} \geq 102)$; and 2$) \mathrm{AC}_{\text {risk-free }}(\mathrm{AC}<102)$ (National Cholesterol Education Program, 2002). The evaluations, always performed by the same physiotherapist, were conducted at three time periods: 1) before $\left(M_{1}\right) ; 2$ ) five minutes after a respiratory physiotherapy session $\left(\mathrm{M}_{2}\right)$; and 3) 30 min after the physiotherapy $\left(\mathrm{M}_{3}\right)$.

The AC was measured in standing, with the measuring tape encircling the abdomen at the midpoint between the lower costal margin and the iliac crest

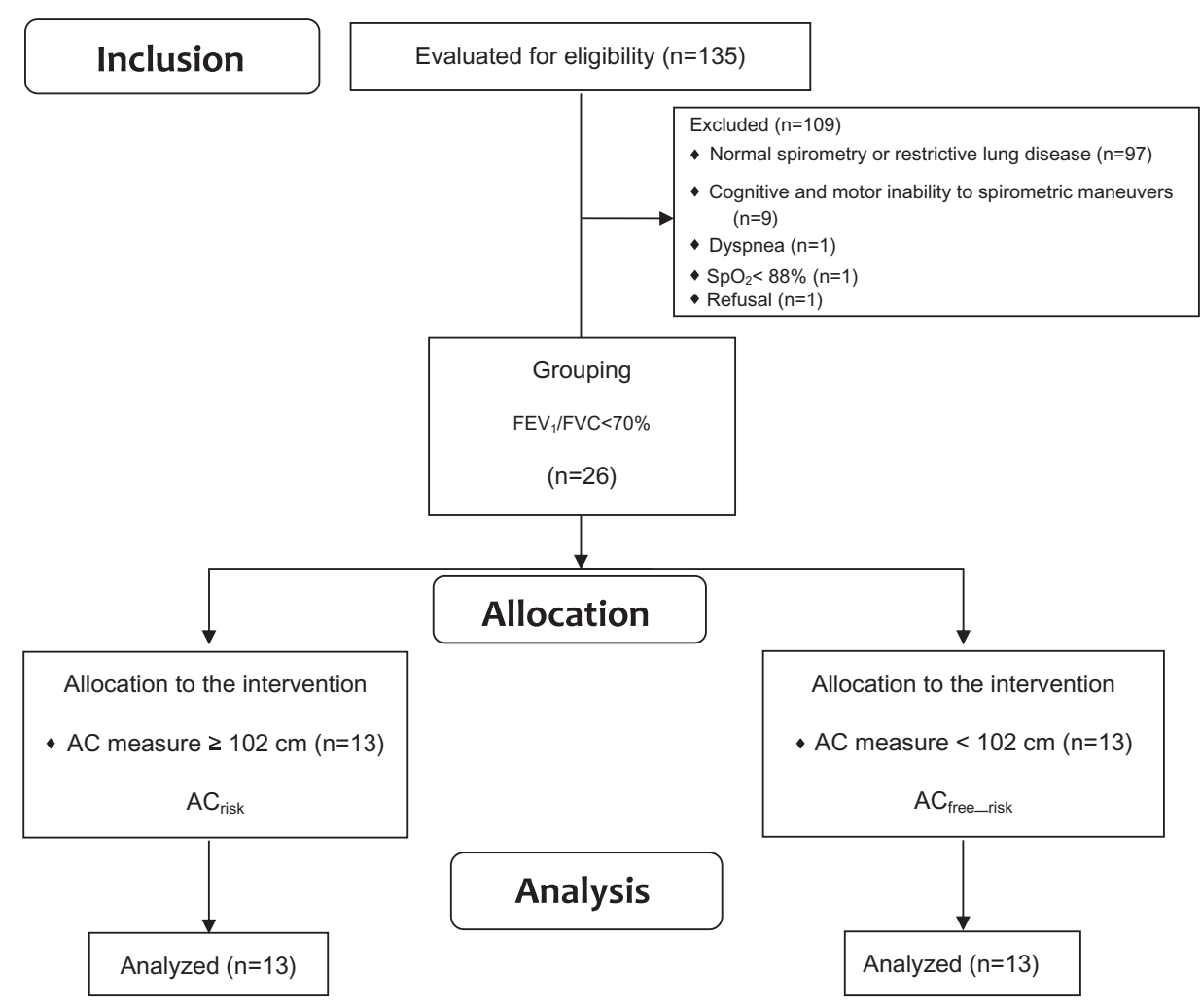

Figure 1. Algorithm representative of the screening process, evaluation and treatment of the men.

Caption: $A C$ : Abdominal Circumference; $A C_{\text {risk }}\left(A C \geq 102 \mathrm{~cm}\right.$ - cardiovascular risk) and $A C_{\text {risk-free }}(A C<102 \mathrm{~cm})$; $F E V_{1}$ : Forced expiratory volume in the first second of Forced Vital Capacity (I); FVC: Forced Vital Capacity (I). 
during normal exhalation (Chan, Watts, Barrett, and Burke, 2003). Body weight $(\mathrm{kg})$ and stature $(\mathrm{cm})$ were evaluated by a calibrated scale that contained a stadiometer (Toledo ${ }^{\circ}$ Brasil), and Body Mass Index (BMI) was calculated (Keys et al., 1972). Biceps, triceps, subscapular and suprailiac skinfolds thickness of the right side of the body were assessed using a Lange adipometer (Beta Technology", Cambridge, MD) and body fat percentage was determined (Durnin and Womersley, 1974). Degree of dyspnea was evaluated using the Medical Research Council (MRC) (Kovelis et al., 2008) and the Borg scale (Borg, 1982).

The HRV was studied by linear analysis using the heart rate recorder RS800CX (Polar Electro Oy, Finlândia). Heart rate (HR) and R-R intervals were examined during a five-minute period in sitting position and it was transferred to a computer by the Polar ProTrainer 5TM software. After visual and software analysis of the records, the ectopic beats or artifact signs were deleted. Only the segments with more than $90 \%$ of pure sinusal beats were included in this analysis. During each time period $\left(\mathrm{M}_{1}, \mathrm{M}_{2}\right.$ and M3) a segment of the HR response was selected containing 256 points and the best sign of stability. After that, data were exported to Kubios HRV (MATLAB, 2.1, Kuopio, Finlândia). The linear analysis of HRV was carried according to the time domain (vagal modulation index of sinus node (rMSSD), standard deviation of all normal RR intervals (SDNN), average of all normal RR intervals (mean $\mathrm{RR}$ ), percentage of consecutive $\mathrm{RR}$ intervals that presented a difference of more than $50 \mathrm{~ms}$ (pNN50) and heart rate average (mean HR)). Frequency domain $(\mathrm{Hz})$ was identified as: low frequency (LF: 0.04-0.15) - sympathetic activity prevalence; and high frequency (HF: 0.15-0.4) - vagal activity; LF/HF-sympathovagal balance. The Poincaré HRV plot analysis yielded the following indexes: SD1-which represents the vagal activity; and SD2-reflecting the general variability (European Society of Cardiology and the North American Society of Pacing and Electrophysiology, 1996; Pumprla et al., 2002).

The $\mathrm{SpO}_{2}(\%)$ and systemic arterial blood pressures were measured by heart monitor (Dixtal DX2022, Biomédica, Brasil) with the participant seated after having rested for five minutes. Capillary blood analysis was measured by Glucose Meter Optium Xceed (Abbott ${ }^{\circ}$, Brasil); range of 20 to $600 \mathrm{mg} / \mathrm{dl}$.

Vital capacity was examined using three reproducible and acceptable measures (Spirobank II MIR ', Itália, Roma), and predictive values were ascertained according to ERS/ Knudson. The participant remained seated after having rested for five minutes (Miller et al., 2005). The maximal inspiratory pressure $\left(\mathrm{PI}_{\max }\right)$ was measured by manovacuometer (Commercial Médica, Brasil) with the scale of \pm $120 \mathrm{cmH}_{2} \mathrm{O}$, which was measured from residual volume
(RV) up to the Total Lung Capacity (TLC) (Black and Hyatt, 1969; Neder, Andreoni, Lerario, and Nery, 1999).

The thoracoabdominal expansibility was measured by means of dynamic cirtometry, using an inextensible measuring tape as instrument. The participants were examined in standing position. The difference between the measurements provided the degree of expansibility and retraction of the thoracoabdominal movements, resulting in determination of the amplitude index (AI) (Jamami, Pires, Oishi, and Costa, 1999).

\section{Respiratory physiotherapy intervention protocol}

Every technique included three series of one minute with a rest interval of one minute between them and was always performed by the same physiotherapist. The participant was placed in a sitting position and instructed to perform diaphragmatic breathing, and expiration with pursed-lips (DPLB) in order to improve lung ventilation. The DPLB was maintained for all other exercises. After correct execution, thoracic vibrocompression technique was added (rhythmic and rapid movements of isometric contraction of the forearm, applied manually, bilaterally, and simultaneously to the anterior chest area, during expiration, associated with chest compressions). Following this maneuver, passive manual expiration technique was performed (slow or quick chest compressions) and once completed the participant was instructed to cough until coughing became dry. After a minute of rest, the participant performed the DPLB associated with movements of the upper limbs-flexion and shoulder extension. Finally, stationary gait was performed for a minute at the participants preferred pace (Dolmage et al., 2013; Rikli and Jones, 1999; Rossi et al., 2014).

\section{Statistical analysis}

To calculate sample size Gpower 3.1 program was used, using spirometric measurements as the primary outcome variable. Alpha value was set for 0.05 and power of $1-\beta$ of 0.08 and 26 participants were required. The Statistical Package for the Social Sciences (SPSS) for Windows version 17.0 (IBM Statistics, Chicago, Illinois, USA) was used for data analysis. The normal distribution of continuous variables was verified by the application of the Shapiro-Wilk test and the homogeneity of variances by the Levene test. In an attempt to standardize the data collected, the transformation of data by $\log _{10}+1$ was applied. Data was expressed descriptively by central average statistical tendency and by data dispersion measurements, mean \pm standard deviation and mean difference (95\% confidence interval). The difference between the values after the intervention and the initial values was 
identified as Delta $(\Delta)$. The categorical variables were presented with absolute and relative frequencies (percentages). For baseline comparison of groups independent $t$ was used. A mixed ANOVA repeated measures $(2 \times 3)$ was applied to test the differences of variables between groups $(\mathrm{AC})$ and the time periods as the independent variables. The adjustment of the comparisons was made by the Bonferroni correction. All tests of significance were 2-tailed and $p$-value of $<0.05$ was considered statistically significant.

\section{Results}

Twenty-six participants with obstructive respiratory disorder took part in this research, with initial and overlapping clinical diagnosis for each group: $\mathrm{AC}_{\text {risk-free: }} 13(60 \%)$ respiratory (e.g. pneumonia); 3 (14\%) gastrointestinal (e.g. dyspepsia); and 3 (14\%) immunologic (e.g. HIV); and $\mathrm{AC}_{\text {risk: }}: 16$ (49\%) respiratory; 9 (27\%) cardiovascular disease (e.g. hypertension); and 2 (6\%) dermatological (e.g. erysipelas) were part of this study. Regarding prescription drugs, digestive system/metabolism (e.g. gastric protectors) and

Table 1. Basal characteristics of the men belonging to defined groups by the abdominal circumference measurement.

\begin{tabular}{lccc}
\hline Variables & $\mathrm{AC}_{\text {risk_free }}$ & $\mathrm{AC}_{\text {risk }}$ & $p$ \\
\hline Age (years) & $50.23 \pm 10.93$ & $61.31 \pm 9.22^{*}$ & .010 \\
MRC dyspnea (0-4) & $1.46 \pm 1.12$ & $1.31 \pm 0.75$ & .844 \\
Borg dyspnea (0-10) & $0.3 \pm 0.6$ & $0.7 \pm 1.0$ & .900 \\
Smoking history (years-pack) & $66.88 \pm 47.66$ & $50.35 \pm 33.81$ & .318 \\
BMl (kg/m ${ }^{2}$ ) & $19.78 \pm 2.92$ & $30.62 \pm 4.34^{*}$ & .001 \\
AC (cm) & $81.46 \pm 9.95$ & $113.54 \pm 8.71^{*}$ & .001 \\
Abdominal body fat (\%) & $15.70 \pm 3.50$ & $30.76 \pm 4.13^{*}$ & .001 \\
\hline
\end{tabular}

Caption: Data presented as mean \pm standard deviation; $\mathrm{AC}$ : abdominal circumference; $A C_{\text {risk }}$ ( $A C \geq 102 \mathrm{~cm}$ - cardiovascular risk) and $A C_{\text {risk-free }}$ $($ AC <102 cm); MRC: Medical Research Council - dyspnea scale; yearspack: quantity of cigarette packs smoked multiplied by the years; BMI: body mass index; ${ }^{*}$ comparison among the groups with significance level of $p<.05$. nervous system (e.g. analgesic drugs) predominated in both groups. Table 1 shows baseline data for age, anthropometry, and respiratory variables of the groups. The $\mathrm{AC}_{\text {risk }}$ group included the oldest men and had the greatest values for anthropometric measurements $(p<0.05)$.

HRV was measured during the assessment and intervention process. The largest changes occurred in $\mathrm{M}_{2}$ and $\mathrm{M}_{3}$ and in the $\mathrm{AC}_{\text {risk-free }}$ group (Figure 2). There was also an increase of the SD2 during $\mathrm{M}_{2}$ in both groups. The SD1 measurement increased after the intervention $\left(\mathrm{M}_{2}\right.$ and $\left.\mathrm{M}_{3}\right)$ in both groups. Diastolic blood pressure (DBP) increased in the $\mathrm{AC}_{\text {risk }}$ group, in $\mathrm{M}_{3}$, approximately $6 \mathrm{mmHg}$ when compared to $M_{1}$. Both groups, in $M_{1}$, had elevated glucose levels $>100 \mathrm{mg} / \mathrm{dl}$, and there was not a statistically significant difference between groups (Table 2).

The $\mathrm{AC}_{\text {risk }}$ group did not display significant respiratory changes in the intra-group analysis, on the other hand, there was an increase in PImax, $\mathrm{FEV}_{1} / \mathrm{FVC}$, Slow Vital Capacity\%-SVC\% and $\mathrm{SpO}_{2} \%$ in the $\mathrm{AC}_{\text {risk-free }}$ group (Figure 3). In addition, the $\mathrm{AC}_{\text {risk-free }}$ group had higher values for the thoracoabdominal mobility measurements at all time periods. Also the $\mathrm{AC}_{\text {risk-free }}$ group axillary AI showed elevated values after intervention, at both $\mathrm{M}_{2}$ and $\mathrm{M}_{3}$ (Table 3).

In the inter-groups comparison, the percentage of Inspiratory Capacity (IC\%) was statistically higher in the $\mathrm{AC}_{\text {risk }}$ group, immediately after the physiotherapeutic intervention $\left(\mathrm{M}_{2}\right)$ (Figure 4). There were no complications during the evaluation and treatment.

\section{Discussion}

The main outcome of this study was that men with obstructive respiratory disorders and abdominal obesity,

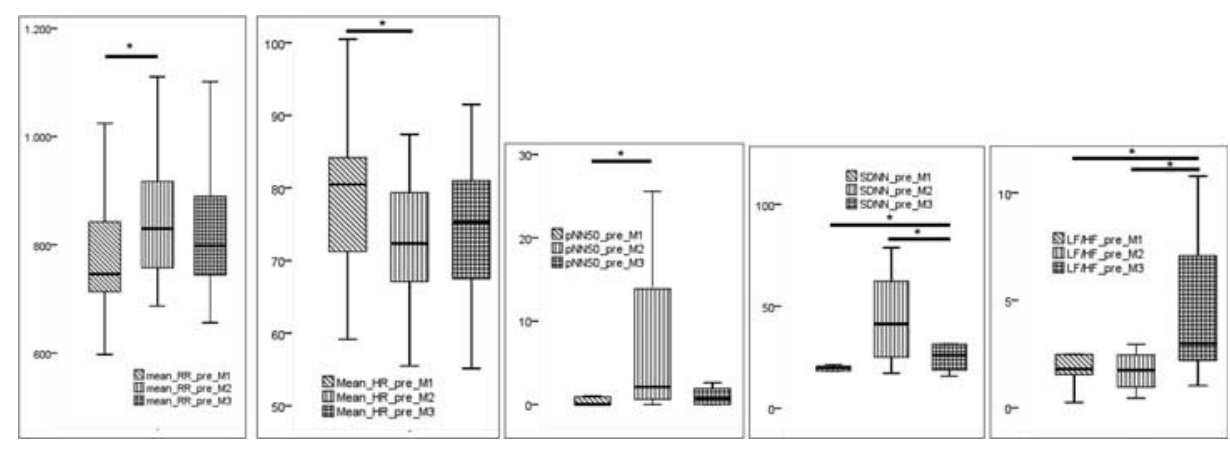

Figure 2. Variables related to cardiac autonomic control, cardiovascular and metabolic in men $(n=13)$ with obstructive respiratory disorder and abdominal circumference $<102 \mathrm{~cm}$ in the initial moment $\left(M_{1}\right)$, immediately post-intervention $\left(M_{2}\right)$ and 30 min later $\left(M_{3}\right)$.

Caption: AC: abdominal circumference, $M$ : moments; $M_{1}$ (diagonal lines): initial moment, $M_{2}$ (vertical lines): immediate moment postprotocol, $\mathrm{M}_{3}$ (checkered): 30 min moment post-protocol, RR: Oscillations of the intervals between consecutive heartbeats; Mean RR (ms): RR intervals of time mean, SDNN (ms): standard deviation of all normal RR intervals (ms), Mean HR (1/min): mean heart rate, pNN50 (\%): percentage of adjacent RR intervals with a difference duration greater than $50 \mathrm{~ms}$, LF: low frequency, HF: high frequency LF/HF (ms ${ }^{2}$ ): the ratio between low and high frequency; $M_{1}$ (diagonal lines): initial moment; $M_{2}$ (vertical lines): immediate moment post-protocol; $M_{3}$ (checkered): 30 min moment post-protocol; *: comparison among moments (intragroup $-p<.05$ ). 


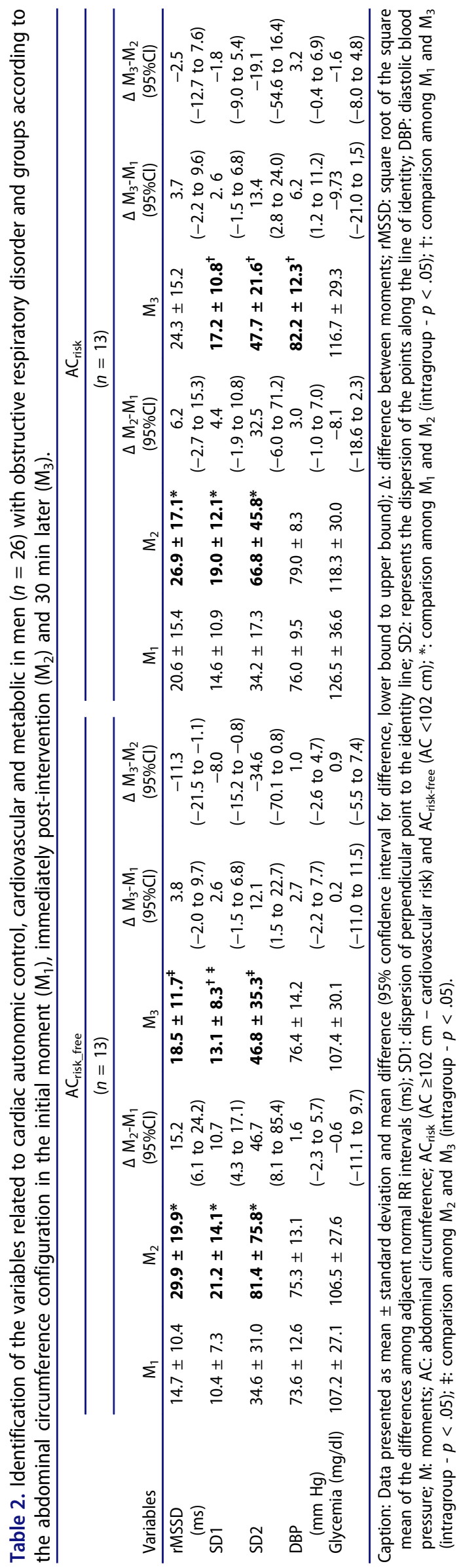



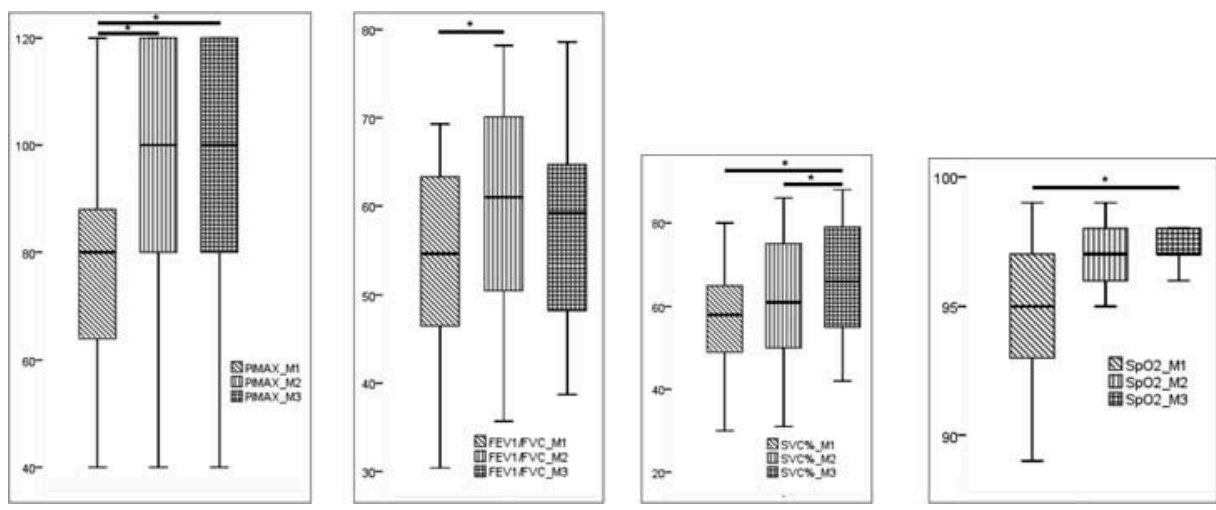

Figure 3. Respiratory variables of the men with obstructive respiratory disorder and the abdominal circumference $<102 \mathrm{~cm}$ in the initial moment $\left(M_{1}\right)$, immediately post-intervention $\left(M_{2}\right)$ and 30 min later $\left(M_{3}\right)$.

Caption: AC: abdominal circumference; $M$ : moments, $M_{1}$ (diagonal lines): initial moment, $M_{2}$ (vertical lines): immediate moment postprotocol, $\mathrm{M}_{3}$ (checkered): 30 min moment post-protocol; $\mathrm{PI}_{\max }\left(\mathrm{cmH}_{2} \mathrm{O}\right)$ : maximal inspiratory pressure, $\mathrm{FEV}_{1} / \mathrm{FVC}$ : Forced expiratory volume in the first second of forced vital capacity (I), FVC: Forced Vital Capacity (I), SVC (\%): Slow Vital Capacity, SpO 2 (\%): peripheral oxygen saturation; *: comparison among moments (intragroup $-p<.05$ ).

when compared to men without obesity, showed lower thoracoabdominal amplitude in all evaluations, and higher IC immediately after respiratory physiotherapy.

\section{$A c_{\text {risk_free }}$ versus $\mathrm{ca}_{\text {risk }}$}

The $\mathrm{CA}_{\text {risk }}$ group was older, almost a 10-year difference, and had higher anthropometric measurements. The sample was one of convenience and age was not controlled.

The process of aging deteriorates physiological systems promoting accumulation of body fat, increasing cardiovascular risk (Aronis et al., 2015) and reducing HRV (American College of Sports Medicine, 2009; European Society of Cardiology and the North American Society of Pacing and Electrophysiology, 1996). However, the $\mathrm{CA}_{\text {risk }}$ group did not show a noticeable difference between the baseline measurements of HRV (Poliakova et al., 2012). In addition, the respiratory system also undergoes changes with advanced age, affecting the rib cage and lung parenchyma (Sharma and Goodwin, 2006).

The higher values of BMI and AC corresponded to lower values of FVC and $\mathrm{FEV}_{1}$. This may be due to increased elastic recoil of the chest wall by the imbalance of structures, mainly to higher levels of tissue in the chest wall. Moreover, diaphragmatic expansion is also mechanically affected (Steier et al., 2009). The compliance of the respiratory system is reduced due to the fact that respiration is performed at abnormally low lung volumes. Normal breathing starts at low-end expiratory volumes where the lungs are less compliant and the airways are prone to collapse during expiration (Behazin, Jones, Cohen, and Loring, 2010). However, pulmonary compression with reduced expiratory reserve volume leads to a compensatory increase in the inspiratory reserve volume (IRV) in an attempt to maintain constant vital capacity (VC) (Costa et al., 2008). The accumulation of adipose tissue along with probable chest tightness/rigidity caused by advanced age are limiting factors that compromise chest expansion (Sharma and Goodwin, 2006; Steier et al., 2009). It can be inferred that these aforementioned mechanisms were probably those which contributed to the reduction of the thoracoabdominal $\mathrm{AI}$ at all time periods in the $\mathrm{CA}_{\text {risk }}$ group.

The $\mathrm{CA}_{\text {risk }}$ group had higher measurements of IC, a $19 \%$ difference, after respiratory intervention $\left(\mathrm{M}_{2}\right)$. IC is higher in obese individuals due to a compensatory increase in the activation of inspiratory muscles against the deposition of fat (Rasslan et al., 2004). Indeed, the IC is likely to change in the presence of obesity and what stands out is that only this spirometric variable was affected, and the explanation for this would be how the spirometric maneuver was performed (i.e. slowly). Therefore, this study suggests that respiratory physiotherapy improves inspiratory capacity of men with increased abdominal circumference and that abdominal obesity limits thoracic expansibility.

\section{$C A_{\text {risk_free }}$}

Because they were thinner and younger, the general condition of the cardiovascular system in the $\mathrm{CA}_{\text {risk_free }}$ group proved to be preserved. The breathing control exercises included in the breathing techniques were useful as an adjunct therapy for cardiorespiratory adjustment (Cooke et al., 1998; Rossi et al., 2014). The HRV increased from $M_{1}$ to $M_{2}$, especially global and vagal modulation. In addition, the variable $\mathrm{HF} / \mathrm{LF}$ showed an increase in $M_{3}$. Increased HRV is a sign of 


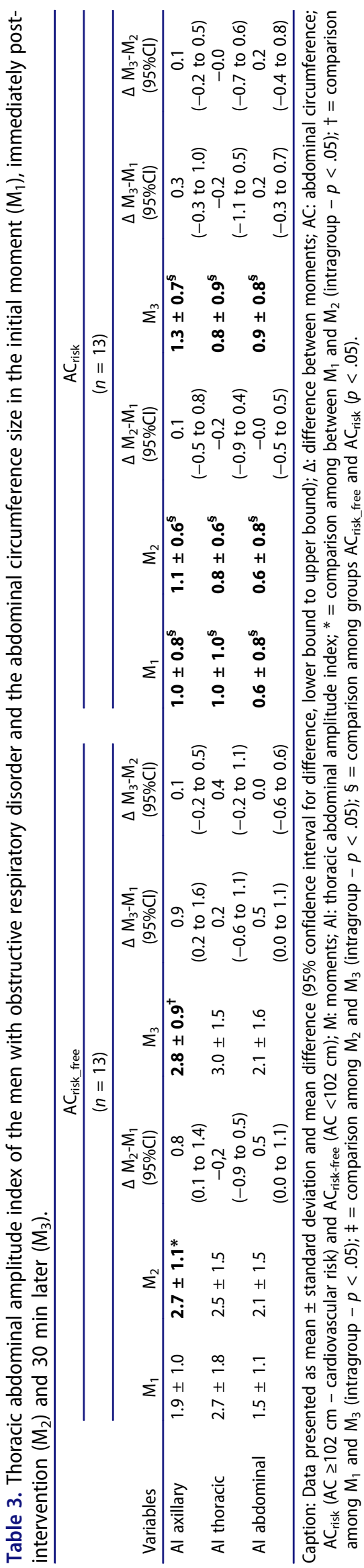

good adaptation, indicating that the autonomic mechanisms are efficient. The increase in vagal activity after $30 \mathrm{~min}$ of physical exercise occurs causing the return to resting values of the variables (Javorka, Zila, Balhárek, and Javorka, 2002). During this time period, the increase in global HRV persisted in these participants, which allows us to infer that there was a satisfactory response after respiratory therapy.

Also, there was a reduction of six bpm $\mathrm{HR}$ $(p<0.05)$, but only in $\mathrm{M}_{2}$, returning to baseline in $\mathrm{M}_{3}$. The fact that performing the respiratory maneuver FVC during spirometric evaluation, specifically for obstructive disease, results in increases of 16 to reductions of $5 \mathrm{bpm}$, without changing the values of BP and HRV indexes (Mendes et al., 2011). The average HR reduction is consistent with the current study. In addition, after physical exercise, heart rate reduction is related to early recovery of the measures of HRV (Javorka, Zila, Balhárek, and Javorka, 2002).

Respiratory changes were more evident in this group and during the $\mathrm{M}_{3}$ period. The protocol was able to improve lung ventilation $\left(\mathrm{FEV}_{1} / \mathrm{FVC}, \mathrm{SVC} \%\right.$ and $\left.\mathrm{SpO}_{2}\right)$, inspiratory muscle strength $\left(\mathrm{PI}_{\max }\right)$ and axillary $\mathrm{AI}$, in a short period of time. The improvement was identified by an increase in SVC $(\Delta: 8.6 \%), \operatorname{SpO} 2(\Delta$ $2.2 \%)$ and axillary AI $(\Delta: 0.8 \mathrm{~cm})$.

There was also an increase in $\mathrm{FEV}_{1} / \mathrm{FVC}$, suggesting airway clearance, either by bronchial hygiene or by the application of respiratory re-education, an important effect for the basal respiratory condition. Reduced adipose tissue was probably the factor that contributed to this good response. These results are consistent with other studies that have applied other techniques different from those applied in the current protocol. These studies have found that individuals undergoing obstructive respiratory intervention tended to increase $\mathrm{PI}_{\max }, \mathrm{SpO}_{2}$, $\mathrm{AI}$ and $\mathrm{FEV}_{1} / \mathrm{FVC}$ (Ali, Talwar, and Jain, 2014; Lan et al., 2013; Rodrigues, Alves, and Gonçalves, 2012).

The increase in $\mathrm{PI}_{\max }$ remained for up to $30 \mathrm{~min}$ after $\mathrm{M}_{2}$, in conjunction with axillary IA. The increased inspiratory muscle function could have been one of the factors that contributed to the increase in thoracic amplitude. Pulmonary clearance could also have contributed to this phenomenon, but the increase was only identified during $\mathrm{M}_{2}$ by the $\mathrm{FEV}_{1} / \mathrm{FVC}$ variable. One can infer that the absence of abdominal obesity and the intervention contributed to a better efficiency of the inspiratory muscles, promoting a certain gain in respiratory muscle performance. This gain may also have contributed to the cardiac autonomic control and respiratory performance, since the $\mathrm{PI}_{\max }$ in COPD correlates with cardiac autonomic control (Reis et al., 2010). 


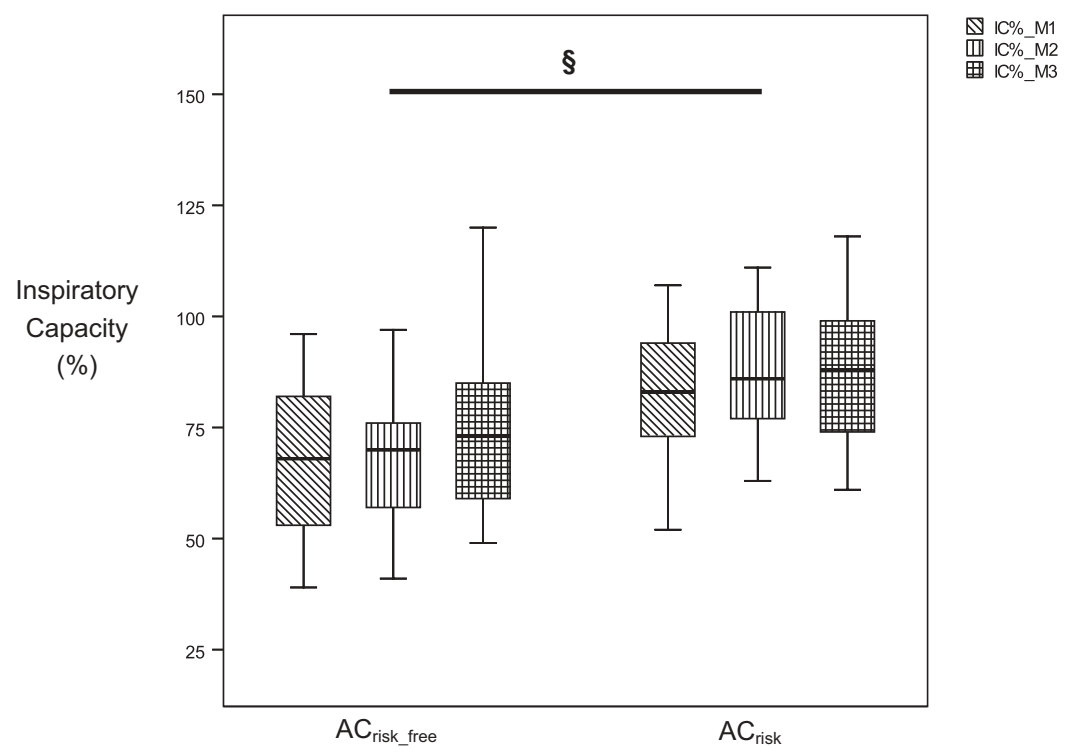

Figure 4. Presentation of the inspiratory capacity percentage (IC\%) in the different moments.

Caption: $A C$ : abdominal circumference; $A C$ : abdominal circumference; $A C_{\text {risk }}\left(A C \geq 102 \mathrm{~cm}\right.$ - cardiovascular risk) and $A C_{\text {risk-free }}(A C<102 \mathrm{~cm})$; $M_{1}$ (diagonal lines): initial moment; $M_{2}$ (vertical lines): immediate moment post-protocol; $M_{3}$ (checkered): 30 min moment post-protocol; IC $\%$ : Inspiratory Capacity percentage; $\S=$ comparison among the groups $A C_{\text {risk_free }}$ and $A C_{\text {risk }}(p<.05)$.

The increase in $\mathrm{SpO}_{2}(\Delta: 2.2 \%)$ may have contributed to both cardiac and respiratory functions, since individuals with COPD are prone to hypoxia, which causes abnormal operation of the Autonomic Nervous System, reduced HRV and abnormal autonomic responses (Scalvini et al., 1998).

\section{$C A_{\text {risk }}$}

In the intra-group analysis, no respiratory changes were noticed, however, long-term studies in obese individuals found changes in these variables and they will be discussed below. Obese individuals undergoing pulmonary rehabilitation showed an increase in $\mathrm{PI}_{\max }(\Delta:-28 \mathrm{~cm}$ $\left.\mathrm{H}_{2} \mathrm{O}\right)$, chest $(\Delta: 1.4)$, xiphoid and abdominal amplitudes $(\Delta: 3 \mathrm{~cm})$ (Costa et al., 2003). Aerobic and resistance exercise increased axillary cirtometry $(\mathrm{cm})(\Delta: 1.58)$ and expiratory xiphoid $(\Delta: 1.68)$ and $\mathrm{PI}_{\max }\left(\Delta:-8.5 \mathrm{cmH}_{2} \mathrm{O}\right)$ (Sonehara et al., 2011). Another study showed an increase in VRI $(\Delta: 0.32 \mathrm{l}), \operatorname{VRE}(\Delta: 0.21 \mathrm{l})$ and axillary mobility $(\Delta: 1.4 \mathrm{~cm})$ (Costa, Forti, Barbalho-Moulim, and Rasera-Junior, 2009).

In the current study which focused on the acute responses following a single intervention session there was an increase in $\mathrm{PI}_{\max }\left(\Delta: 7.4 \mathrm{cmH}_{2} \mathrm{O}\right)$ and up to $0.3 \mathrm{~cm}$ in thoracoabdominal amplitudes, but without statistical significance. Perhaps, for this population, repeated acute responses demanding more effort, causing higher stimulation, either by the imposition of load or the number of sets and repetitions, might reduce obstruction and overcome the restrictive factors caused by excessive adipose tissue.

It became evident that for obese men with COPD, acute changes occur only in the cardiac variables. HRV increased in the $\mathrm{CA}_{\text {risk }}$ group after respiratory therapy with a predominance of vagal modulation even after $30 \mathrm{~min}$ post-exercise identifying a useful response.

A protocol of respiratory and lower limb exercises, performed in hospitalized overweight individuals, caused reduction in $\mathrm{rMSSD}$ and $\mathrm{AF}$, increased $\mathrm{LF} / \mathrm{HF}$ ratio, systolic blood pressure $(\Delta: 6 \mathrm{mmHg})$ and Heart Frequency ( $\Delta: 9 \mathrm{bpm})$ (Hiss et al., 2012). Despite the similarities between this population (Hiss et al., 2012) and the current study, with regard to risk and cardiovascular compromise (increase in AC and cardiac event), the intervention applied in the present study generated an increase in the HRV index which contributed to a better cardiac autonomic modulation.

Another finding in this group was the rise in diastolic blood pressure (DBP) at $\mathrm{M}_{3}$. It is important to note that the pressure change after exercise is dependent on neural mechanisms and peripheral vascular resistance (PVR). Thus, the inhibition of sympathetic activity and the reduction in circulating hormones, post-exercise, led to a reduction of PVR and HR, and an increase in baroreflex sensitivity (American College of Sports Medicine, 2009; Gonçalves et al., 2015; Halliwill, Taylor, and Eckberg, 1996; Whelton, Chin, Xin, and He, 2002; Wolthuis, Froelicher, Fischer, and Triebwasser, 1977). 
Despite the increase in post-intervention DBP, the rise observed was only $6.2 \mathrm{mmHg}$, which is lower than an elevation of 10 to $15 \mathrm{mmHg}$ regarded as important in other studies (Akhras, Upward, and Jackson, 1985; Pescatello et al., 2004). One reason that may explain this is the change in the regulation of vascular reactivity present in cardiovascular and metabolic diseases (Brett, Ritter, and Chowienczyk, 2000). The $\mathrm{CA}_{\text {risk }}$ group showed characteristics of Metabolic Syndrome (i.e. 29\% of the men had diagnosis related to cardiovascular diseases). In addition, the basal blood glucose was $126.5 \pm 3.6 \mathrm{mg} / \mathrm{dl}$, indicating a metabolic change in the glycemic profile (American Diabetes Association, 2016). Furthermore, advanced age tends to increase PVR, which would also explain the poor response of the post-exercise DBP (American College of Sports Medicine, 2009).

This study is original for investigating the effects of respiratory physiotherapy on the condition of obstructive respiratory disorders and increased abdominal circumference and has contributed to the current body of knowledge in this area by identifying that a single respiratory session promotes benefits to these individuals. It is clear that respiratory therapy in the hospital improves cardiac autonomic modulation by decreasing sympathetic influence. This increased parasympathetic modulation can improve the prognosis of individuals with COPD that are obese or not.

\section{Study limitations}

Studying AC separately can generate possible confounders. When studying the anthropometric measurements, such as BMI and CA, it is difficult to understand and differentiate these elements, their interferences, since they are interrelated anthropometric factors. It is worth noting that BMI above normal is not indicative of a high AC. In contrast, the AC is the measure of fatness that takes into account the accumulation of fat in the abdominal cavity. However, the main focus of this study was to AC.

Some medications may alter cardiorespiratory responses but all participants were medicated according to their care situation or hospitalization. The use of medications was imperative for these participants and there was not possibility to reduce or withhold these medications.

Restricting the study to male participants increased the internal validity of the study and eliminated the possibility of gender bias. The deposition of body fat differs between genders, being more central in men and more peripheral in women. The findings allow inference only in males, and cannot be extrapolated to women.

\section{Conclusions}

The increased AC measurement which represents increased risks for cardiovascular diseases, in men with obstructive respiratory disorders, limits the thoracoabdominal expansibility and induces rise of the diastolic blood pressure, however respiratory physiotherapy promotes increase in cardiac modulation and inspiratory capacity.

\section{Declaration of Interest}

The authors report no declarations of interest.

\section{References}

Akhras F, Upward J, Jackson G 1985 Increased diastolic blood pressure response to exercise testing when coronary artery disease is suspected an indication of severity. British Heart Journal 53: 598-602.

Ali MS, Talwar D, Jain SK 2014 The effect of a short-term pulmonary rehabilitation on exercise capacity and quality of life in patients hospitalized with acute exacerbation of chronic obstructive pulmonary disease. Indian Journal of Chest Diseases and Allied Sciences 56: 13-19.

American Diabetes Association 2016 Standards of medical care in diabetes. Diabetes Care 39: 1-119.

Aronis KN, Wang N, Phillips CL, Benjamin EJ, Marcus GM, Newman AB, Rodondi N, Satterfield S, Harris TB, Magnani JW, Health ABC Study 2015 Associations of obesity and body fat distribution with incident atrial fibrillation in the biracial health aging and body composition cohort o folder adults. American Heart Journal 170: 498-505.

Behazin N, Jones SB, Cohen RI, Loring SH 2010 Respiratory restriction and elevated pleural and esophageal pressures in morbid obesity. Journal of Applied Physiology 108: 212-218.

Black LF, Hyatt RE 1969 Maximal respiratory pressures: normal values and relationship to age and sex. American Review of Respiratory Disease 99: 696-702.

Borg GA 1982 Psychophysical bases of perceived exertion. Medicine and Science in Sports and Exercise 14: 377-381.

Brett SE, Ritter JM, Chowienczyk PJ 2000 Diastolic blood pressure changes during exercise positively correlate with serum cholesterol and insulin resistance. Circulation 101: 611-615.

Bruurs ML, Giessen LJ, Moed H 2013 The effectiveness of physiotherapy in patients with asthma: a systematic review of the literature. Respiratory Medicine 107: 483-494.

Chan DC, Watts GF, Barrett PH, Burke V 2003 Waist circumference, waist-to-hip ratio and body mass index as predictors of adipose tissue compartments in men. QJM: Monthly of the Association of Physicians 96: 441-447.

Chen R, Tunstall-Pedoe H, Bolton-Smith C, Hannah MK, Morrison C 2001 Association of dietary antioxidants and waist circumference with pulmonary function and airway obstruction. American Journal of Epidemiology 153: 157-163. 
American College of Sports Medicine, Chodzko-Zajko WJ, Proctor DN, Fiatarone Singh MA, Minson CT, Nigg CR, Salem GJ, Skinner JS 2009 American college of sports medicine position stand. Exercise and physical activity for older adults. Medicine and Science in Sports and Exercise 41: 1510-1530.

Cooke WH, Cox JF, Diedrich AM, Taylor JA, Beightol LA, Ames JE, Hoag JB, Seidel H, Eckberg DL 1998 Controlled breathing protocols probe human autonomic cardiovascular rhythms. American Journal of Physiology 274: 709-718.

Costa D, Barbalho MC, Miguel GP, Forti EM, Azevedo JL 2008 The impact of obesity on pulmonary function in adult women. Clinics 63: 719-724.

Costa D, Forti EM, Barbalho-Moulim MC, Rasera-Junior L 2009 Estudo dos volumes pulmonares e da mobilidade toracoabdominal de portadoras de obesidade mórbida, submetidas à cirurgia bariátrica, tratadas com duas diferentes técnicas de fisioterapia. Brazilian Journal of Physical Therapy 13: 294-300.

Costa D, Sampaio LMM, Lorenzzo VAP, Jamami M, Damaso AR 2003 Avaliação da força muscular respiratória e amplitudes torácicas e abdominais após a RFR em indivíduos obesos. Revista Latino-Americana De Enfermagem 11: 156-160.

Dechman G, Wilson CR 2004 Evidence underlying breathing retraining in people with stable chronic obstructive pulmonary disease. Physical Therapy 84: 1189-1197.

Dolmage TE, Janaudis-Ferreira T, Hill K, Price S, Brooks D, Goldstein RS 2013 Arm elevation and coordinated breathing strategies in patients with COPD. Chest 144: $128-135$

Durnin JV, Womersley J 1974 Body fat assessed from the total body density and its estimation from skinfold thickness: measurements on 481 men and women aged from 16 to 72 years. British Journal of Nutrition 32: 77-97.

European Society of Cardiology and the North American Society of Pacing and Electrophysiology 1996 Heart rate variability: standards of measurement, physiological interpretation and clinical use. Circulation 93: 1043-1065.

Ferreira LL, Souza NM, Bernardo AF, Vitor ALR, Valenti VE, Vanderlei LC 2013 Variabilidade da frequência cardíaca como recurso em fisioterapia: análise de periódicos nacionais. Fisioterapia Em Movimento 26: 25-36.

Gonçalves AC, Vanderlei LC, Monteiro BM, Carvalho TD, Rossi RC, Fernandes RA, Pastre CM, Abreu LC 2015 Effect of acute resistance exercise in different intensities and body segments on cardiovascular variables. International Archives of Medicine 8: 1-12.

Halliwill JR, Taylor JA, Eckberg DL 1996 Impaired sympathetic vascular regulation in humans after acute dynamic exercise. Journal of Physiology 495: 279-288.

Hiss MD, Neves VR, Hiss FC, Silva E, Silva AB, Catai AM 2012 Segurança da intervenção fisioterápica precoce após o infarto agudo do miocárdio. Fisioterapia Em Movimento 25: $153-163$.

Huxley R, Mendis S, Zheleznyakov E, Reddy S, Chan J 2010 Body mass índex, waist circumference and waist: hipratio as predictors of cardiovascular risk - A review of the literature. European Journal of Clinical Nutrition 64: 16-22.

Jamami M, Pires VA, Oishi J, Costa D 1999 Efeitos da intervenção fisioterápica na reabilitação pulmonar de sujeitos com doença pulmonar obstrutiva crônica
(DPOC). Revista De Fisioterapia Da Universidade De São Paulo 6: 140-153.

Javorka M, Zila I, Balhárek T, Javorka K 2002 Heart rate recovery after exercise: relations to heart rate variability and complexity. Brazilian Journal of Medical and Biological Research 35: 991-1000.

Keys A, Fidanza F, Karvonen MJ, Kimura N, Taylor HL 1972 Indices of relative weight and obesity. Journal of Chronic Diseases 25: 329-343.

Kleiger RE, Stein PK, Bigger JT Jr 2005 Heart rate variability: measurement and clinical utility. Annals of Noninvasive Electrocardiology 10: 88-101.

Kovelis D, Segretti NO, Probst VS, Lareau SC, Brunetto AF, Pitta F 2008 Validação do modified pulmonary functional status and dyspnea questionnaire e da escala do medical research council para o uso em pacientes com doença pulmonar obstrutiva crônica no Brasil. Jornal Brasileiro De Pneumologia 34: 1008-1018.

Lan CC, Chu WH, Yang MC, Lee CH, Wu YK, Wu CP 2013 Benefits of pulmonary rehabilitation in patients with COPD and normal exercise capacity. Respiratory Care 58: $1482-1488$

Mendes FA, Moreno IL, Durand MT, Pastre CM, Ramos EM, Vanderlei LC 2011 Análise das respostas do sistema cardiovascular ao teste de capacidade vital forçada na DPOC. Brazilian Journal of Physical Therapy 15: 102-108.

Miller MR, Hankinson J, Brusasco V, Burgos F, Casaburi A, Coates A, Enright P,M, van der Grinten CP, Gustafsson P, Jensen R, et al 2005 Standardisation of spirometry. Series "ATS/ERS Task force: standardization of lung function testing”. European Respiratory Journal 26: 319-338.

National Cholesterol Education Program (NCEP) Expert Panel on Detection, Evaluation, and Treatment of High Blood Cholesterol in Adults (Adult Treatment Panel III) 2002 Third Report of the National Cholesterol Education Program (NCEP) expert panel on detection, evaluation, and treatment of high blood cholesterol in adults (Adult Treatment Panel III) final report. Circulation 106: 31433421.

Neder JA, Andreoni S, Lerario MC, Nery LE 1999 Reference values for lung function tests. II. Maximal respiratory pressures and voluntary ventilation. Brazilian Journal of Medical and Biological Research 32: 719-727.

Pantoni CB, Reis MS, Martins LE, Catai AM, Costa D, Borghi-Silva A 2007 Estudo da modulação autonômica da frequência cardíaca em repouso de sujeitos idosos com doença pulmonar obstrutiva crônica. Brazilian Journal of Physical Therapy 11: 35-41.

Pescatello LS, Franklin BA, Fagard R, Farquhar WB, Kelley GA, Ray CA, ACSM 2004 American college of sports medicine position stand. Exercise and hypertension. Medicine and Science in Sports and Exercise 36: 533-553.

Poliakova N, Déspres JP, Bergeron J, Alméras N, Tremblay A, Poirier P 2012 Influence of obesity índices, metabolic parameters and age on cardiac autonomic function in abdominally obese men. Metabolism 61: 1270-1279.

Pumprla J, Howorka K, Groves D, Chester M, Nolan J 2002 Functional assessment of heart rate variability: physiological basis and practical applications. International Journal of Cardiology 84: 1-14. 
Rasslan Z, Junior Saad R, Stirbulov R, Fabri RM, Lima CA 2004 Evaluation of pulmonary function in class I and II. Jornal Brasileiro De Pneumologia 30: 508-514.

Reis MS, Arena R, Deus AP, Simões RP, Catai AM, Borghi-Silva A 2010 Deep breathing heart-rate variability is associated with respiratory muscle weakness in patients with chronic obstructive pulmonary disease. Clinics 65: 369-375.

Rikli RE, Jones CJ 1999 Development and validation of a functional fitness test for community-residing older adults. Journal of Aging and Physical Activity 7: 129-161.

Rodrigues CP, Alves LA, Gonçalves CG 2012 Efeito de um programa de exercícios direcionados à mobilidade torácica na DPOC. XVI Simpósio Internacional de fisioterapia respiratória e fisioterapia em terapia intensiva. Resumo. Brazilian Journal of Physical Therapy 16: 1.

Rossi RC, Vanderlei FM, Bernardo AF, Souza NM, Goncalves AC, Ramos EM, Pastre CM, Abreu LC, Vanderlei LC 2014 Effect of pursed-lip breathing in patients with COPD: linear and nonlinear analysis of cardiac autonomic modulation. Copd 11: 39-45.

Rossi RC, Vanderlei LC, Gonçalves AC, Vanderlei FM, Bernardo AF, Yamada KM, da Silva NT, de Abreu LC 2015 Impact of obesity on autonomic modulation, heart rate and blood pressure in obese young people. Autonomic Neuroscience 193: 138-141.

Scalvini S, Porta R, Zanelli E, Volterrani M, Vitacca M, Pagani M, Giordano A, Ambrosino N 1998 Effects of oxygen on autonomic nervous system dysfunction in patients with chronic obstructive pulmonary disease. European Respiratory Journal 13: 119-124.

Schans CP 2007 Conventional chest physical therapy for obstructive lung disease. Respiratory Care 52: 1198-1206.

Sharma G, Goodwin J 2006 Effect of aging on respiratory system physiology and immunology. Clinical Interventions in Aging 1: 253-260.

Sharp JT 1985 Therapeutic considerations in respiratory muscle function. Chest 88: 118-123.

Sidney S, Sorel M, Quesenberry CP Jr, DeLuise C, Lanes S, Eisner MD 2005 COPD and incident cardiovascular disease hospitalizations and mortality: kaiser Permanente Medical Care Program. Chest 128: 2068-2075.

Sonehara E, Cruz MSL, Fernandes PR, Policarpo F, Fernandes Filho J 2011 Efeitos de um programa de reabilitação pulmonar sobre mecânica respiratória e qualidade de vida de mulheres obesas. Fisioterapia Em Movimento 24: 13-21.

Steier J, Jolley CJ, Seymour J, Roughton M, Polkey MI, Moxham J 2009 Neural respiratory drive in obesity. Thorax 64: 710-725.

Whelton SP, Chin A, Xin X, He J 2002 Effect of aerobic exercise on blood pressure: a meta-analysis of randomized, controlled trials. Annals of Internal Medicine 136: 493503.

Wolthuis RA, Froelicher VF Jr, Fischer J, Triebwasser JH 1977 The response of healthy men to treadmill exercise. Circulation 55: 153-157. 